\title{
ESTUDO DE ENVOLTÓRIAS PARAMÉTRICAS PERFORMATIVAS EM EDIFÍCIOS VERTICAIS ${ }^{1}$
}

\author{
PARAMETRIC PERFORMATIVE ENVELOPES STUDY IN TALL BUILDINGS
}

\author{
Filipe Campos \\ LAPAC, Faculdade de Engenharia Civil, Arquitetura e Urbanismo, UNICAMP \\ f m campos@yahoo.com.br \\ Maria Gabriela Celani \\ LAPAC, Faculdade de Engenharia Civil, Arquitetura e Urbanismo, UNICAMP \\ celani@fec.unicamp.br
}

\begin{abstract}
Resumo
Ferramentas como parametrização e simulações computacionais têm mudando a forma de se projetar em arquitetura, permitindo inserir parâmetros de materiais, produção e desempenho no projeto desde seus primeiros estágios. Essa inserção permite criar soluções integradas entre o projeto arquitetônico e outros, como o projeto estrutural, numa solução mais eficiente. Quando estas soluções integradas respondem ao desempenho do edifício e buscam melhorá-lo, chamamos o resultado de arquitetura performativa. Entre as vantagens de sua aplicação, podemos citar o melhor uso de materiais, redução de gastos energéticos com condicionamento de ar etc. Esta pesquisa, ainda em desenvolvimento, explora a aplicação de métodos e ferramentas computacionais no projeto visando à arquitetura performativa. Este trabalho apresenta o desenvolvimento e resultados de um exercício de projeto, onde se buscou melhorar o desempenho estrutural e de ganho térmico, através da parametrização e de simulações computacionais.
\end{abstract}

Palavras-chave: Arquitetura Performativa. Ganho Térmico. Estrutura. Parametrização. Otimização.

\begin{abstract}
Tools such as parameterization and computational simulations are changing the way architects design, allowing inserting materials, production and performance parameters since the early stages of the design process. This use permits to create integrated solutions between the architectonic project and other, such as the structural project, into a more efficient solution. When these integrated solutions respond to the performance of the building and seek to improve it, it's called performative architecture. Among the advantages of its application, we can quote the best use of materials, reduction of energy costs with air conditioning etc. This ongoing research explores the application of methods and computational tools in the design project, aiming at performative architecture. This work presents the development and results of a design exercise, where it aimed to improve the structural performance and solar gain through parameterization and computational simulations.
\end{abstract}

Keywords: Performative Architecture. Solar Gain. Structure. Parametrization. Optimization.

\section{INTRODUÇÃO}

O desenvolvimento e uso das ferramentas de CAD e CAM na arquitetura vem gerando diversas revoluções na arquitetura. Estas não se dão somente pela exploração formal de superfícies NURBS, mas também, pela inserção de técnicas que permitem maior

\footnotetext{
${ }^{1}$ CAMPOS, F.; CELANI, M. Estudo de envoltórias paramétricas performativas em edifícios verticais. In: ENCONTRO BRASILEIRO DE TECNOLOGIA DE INFORMAÇÃO E COMUNICAÇÃO NA CONSTRUÇÃO, 7. 2015, Recife. Anais... Porto Alegre: ANTAC, 2015.
} 
complexidade ao projeto, inserindo importantes qualidades materiais, tecnológicas e de desempenho. Inclusive, modificando a forma de trabalho entre arquitetos e outros profissionais, como engenheiros civis.

No Modernismo, havia uma nítida separação entre o trabalho do arquiteto e do engenheiro civil, onde o primeiro concebia a solução formal, para que o segundo pudesse inserir a solução estrutural. Com a atual revolução da arquitetura, ambos os profissionais trabalham em conjunto desde o início do processo de projeto (OXMAN; OXMAN, 2010). Esta alteração de paradigma permite inserir parâmetros estruturais, materiais, de fabricação e de desempenho, criando soluções integradas através de exploração criativas.

Um dos métodos para se chegar nestas soluções integradas é pelo uso da parametrização, onde mantêm-se as relações topológicas entre os elementos, alterando-se somente o valor de seus parâmetros (BURRY; BURRY, 2010). Ao utilizar este método, em conjunto com simulações computacionais, é possível utilizar o desempenho do edifício como parâmetro para a busca destas soluções integradas em determinados quesitos.

Quando a forma ou distribuição dos elementos de uma obra arquitetônica resulta da busca em melhorar o desempenho do edifício nestes determinados quesitos, podemos chamá-la de arquitetura performativa (KOLAREVIC; MALKAWI, 2005). Deste modo, o arquiteto não idealiza a forma final destes elementos arquitetônicos, mas sim suas relações topológicas, permitindo que os elementos se adequem às necessidades da obra.

Existem diversas abordagens para se chegar numa arquitetura performativa, dependendo dos quesitos que devem ser otimizados, seus objetivos e suas restrições. Num primeiro momento, podemos separar em duas abordagens básicas: onde há mudança da forma do edifício e onde não há. No caso de mudança da forma, esta é gerada ou modificada de acordo com os quesitos de desempenho, mantendo suas relações topológicas. Deste modo, os limitantes são, por exemplo, a secção da estrutura ou tamanho de seus componentes, onde a forma se adequa à solução estrutural otimizada.

No segundo caso, a forma é concebida inicialmente e não se altera em relação ao desempenho, sendo que outros aspectos, como padrão da envoltória, estrutura, aberturas etc. são modificadas quanto à sua geometria e disposição. Esta restrição se dá quando a forma já está respondendo a questões como legislação, programa arquitetônico, intenção arquitetônica, inserção urbana, implantação ou outros.

O objetivo principal da pesquisa é explorar as possibilidades de incorporação de ferramentas computacionais na fase inicial do processo de projeto de arquitetura, tendo como foco a arquitetura performativa. Para tal, estão sendo utilizados diversos estudos de caso e exercícios de projetos com diversos métodos de otimização do desempenho.

Como estudos de casos, estão sendo analisadas obras arquitetônicas que buscaram a otimização estrutural ou redução de ganho térmico através da parametrização aliada a analises computacionais, otimização por algoritmos genéticos ou uso de sistemas generativos. As obras são modeladas parametricamente e o método de otimização é aplicado a estas, buscando reproduzir o resultado presente na obra. Os métodos podem então serem aplicados em outras obras arquitetônicas, analisando qual é o mais adequado para cada obra, de acordo as necessidades e restrições desta. Além disso, são aplicados em exercícios de projeto, buscando analisar suas restrições e aplicações.

Neste trabalho, será apresentado um exercício de projeto que segue a segunda abordagem, onde se manteve a forma concebida anteriormente, modificando aspectos de sua envoltória quanto ao seu desempenho. A pesquisa se focou nos aspectos estruturais e de ganho térmica da envoltória, trabalhando com a secção da estrutura e elementos leves de sombreamento perfurados. 


\section{MATERIAIS E MÉTODOS}

A pesquisa, ainda em desenvolvimento, é do tipo experimental e possuí caráter exploratório, inserindo-se na área de Building Performance Simulation (BPS). Esta está sendo desenvolvida com base no programa de modelagem Rhinoceros $5 R S 11$ e seu plug-in Grasshopper (versão 0.9.0076), sendo também utilizado o programa Ecotect Analysis 2011 e os plug-ins Geco (versão 1.0.43.0) e Karamba (versão 1.1).

O programa Rhinoceros é um programa de modelagem NURBS, permitindo trabalhar com superfícies complexas e de múltiplas curvaturas, enquanto seu plug-in Grasshopper permite parametrizar esta modelagem, mantendo as relações topológicas e automatizando as operações realizadas durante a aplicação dos métodos de otimização.

Para as análises estruturais foi utilizado o plug-in Karamba, que, dentre os plug-ins disponíveis para trabalhar dentro do Grasshopper, apresenta as tensões em cada barra num formato que pode ser facilmente trabalhado no Grasshopper. Por não haver necessidade de exportar o modelo para outro programa e depois importar os dados de tensões, requer menos tempo de processamento, agilizando o processo de otimização e modificações.

Para a otimização de ganho térmico, foi utilizado o programa Ecotect e o plug-in Geco, que faz a ligação entre o Ecotect e o Grasshopper. O programa foi escolhido por ter sido usado em pesquisa anterior por parte dos autores. e fornecer a insolação das faces num formato lido pelo Grasshopper. Algumas ressalvas quanto ao seu uso são feitas no item "Considerações Finais", que serão levadas em conta na continuação da pesquisa e pesquisas futuras.

Como citado na introdução, o exercício de projeto se baseia da definição de uma forma básica com posterior aplicação de métodos de otimização. A otimização estrutural se dará pela aplicação de diferentes secções às barras, de acordo com sua tensão, enquanto a otimização do ganho térmico se dará pela aplicação de aberturas na envoltória do edifício, controlando a insolação nas paredes do edifício.

O exercício de projeto pode ser dividido em seis etapas: definição da forma básica, triangulação da superfície e extração da estrutura em treliça, análise estrutural, otimização estrutural, análise de insolação e aplicação de padrões de aberturas na envoltória.

\subsection{Modelagem}

A forma do edifício vertical deveria apresentar uma superfície contínua com múltiplas curvaturas, sendo irregular e assimétrica. Desta forma, tanto a distribuição de cargas no edifício quanto o ganho solar em cada área deste seria diferente, apresentando peças únicas para cada área. Estas condições foram inseridas para testar e demonstrar o uso dos métodos aplicados em geometrias complexas.

A secção horizontal mais simples para ter-se uma superfície contínua seria uma circunferência, contudo a interpolação de duas circunferências só iria gerar superfícies de uma curvatura. Com o uso de duas elipses não colineares, é possível gerar uma superfície contínua de múltiplas curvaturas e assimétrica, respondendo aos quesitos formais impostos.

A modelagem foi feita tendo como base a interpolação de duas elipses, uma na base e a outra no topo, com os seus eixos maiores orientados em direções ortogonais diferentes ( $\mathrm{X}$ e Y). Suas dimensões, diferença de altura entre estas e posição em relação à origem foram utilizadas como parâmetros. Esta forma pôde responder aos quesitos impostos, sendo modelada a partir de formas geométricas simples e operações simples. 


\subsection{Triangulação}

Para se extrair a estrutura e superfície para o cálculo de ganho térmico, a fachada do edifício foi triangulada. Este processo facilita os demais, desde os cálculos à construção, pois apresenta elementos estruturais retos e subsuperfícies planas. Existem diversos métodos de triangulação de superfícies sendo que, neste caso, foi utilizado um componente de triangulação que desenvolvemos em uma pesquisa anterior, que se baseia na triangulação de quadriláteros.

A triangulação por quadriláteros se baseia em dividir a superfície em subsuperfícies isoparamétricas a partir dos parâmetros $\mathrm{U}$ e V. Estas subsuperfícies quadriláteras ainda apresentam múltiplas curvaturas, sendo necessário extrair seus vértices e ordená-los em duas superfícies triangulares planas, com arestas retas (Figura 1).

Figura 1 - Triangulação da superfície

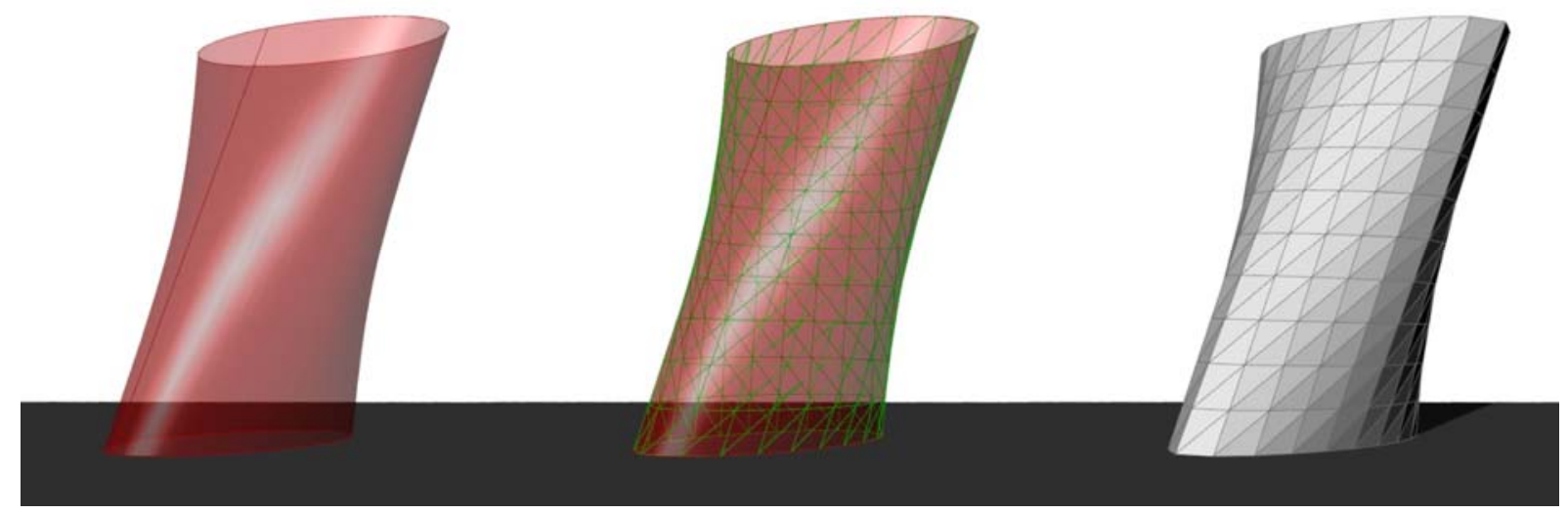

Fonte: Dos autores.

\subsection{Análise estrutural}

A partir da triangulação da forma, foi possível extrair a estrutura do edifício, utilizando as arestas das superfícies triangulares. A estrutura resultante se assemelha a uma treliça, possuindo barras horizontais, verticais e diagonais. Preferiu-se o uso desta estrutura por acompanhar a triangulação da fachada, além de sua estabilidade fornecida pelos travamentos diagonais desta.

Foram selecionados como pontos de apoio os vértices pertencentes ao plano $\mathrm{XY}$, sendo considerados apoios fixos, sem translação ou rotação nas três direções ortogonais. Para a aplicação de cargas, foi considerada a aplicação pontual nos vértices do topo, igualmente distribuída entre estes. O plug-in permite a utilização de diversos tipos de apoios e aplicação de cargas, bem como inserir informações dos materiais. Como se trata de um dos primeiros estudos da pesquisa buscou-se criar um modelo simplificado de análise estrutural, utilizando inclusive informações padrão sobre os materiais estruturais.

Como se pode ver na Figura 2, o plug-in fornece visualmente as deformações nas barras (deve-se atentar que se trata de uma deformação dramática, onde as dimensões da deformação são intensificadas para fácil visualização), bem como a identificação por cor das forças de tensão nas barras: barras azuis correspondem à tração e barras vermelhas à compressão, sendo que quanto mais próximas da cor branca, menor é a tensão na barra. Além das informações visuais, são fornecidos também os valores das forças normais, bem como o momento em cada barra e a força cortante. 
Figura 2 - Análise estrutural

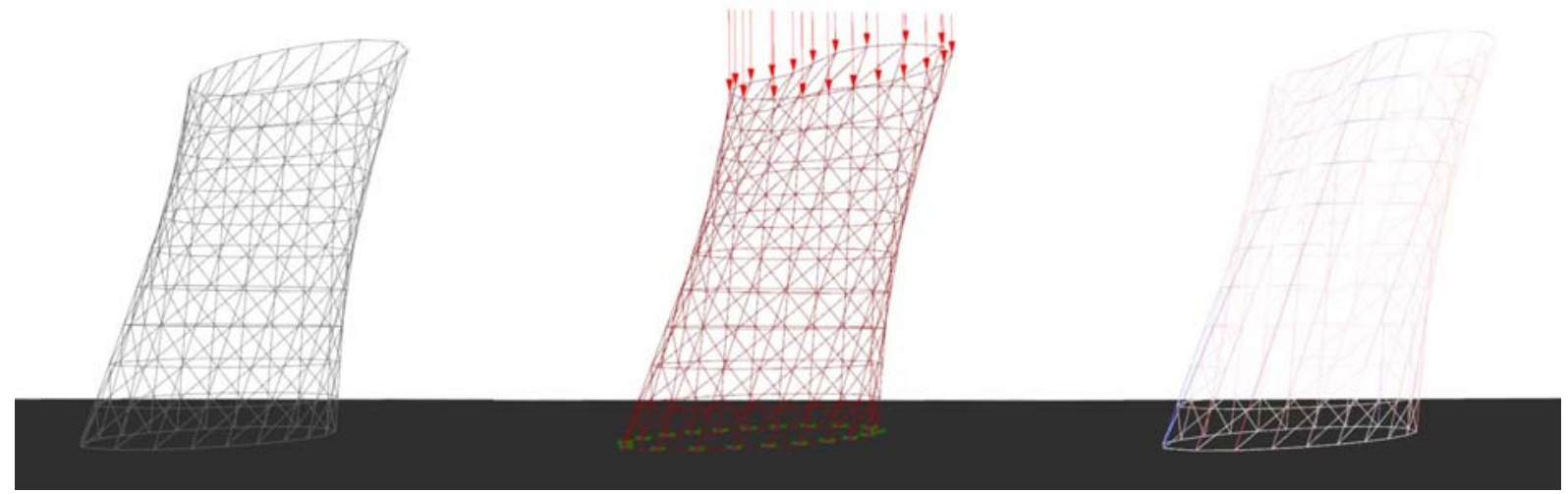

Fonte: Dos autores.

\subsection{Otimização estrutural}

A partir dos resultados da análise estrutural, podem-se dividir as barras entre compressão e tração. Como os materiais costumam ter diferentes tolerâncias em relação à compressão e tração, preferiu-se utilizar diferentes valores para cada, buscando utilizar o material da melhor forma.

Os dois grupos foram subdivididos em quatro subgrupos, onde cada um correspondia a um intervalo de tensão. Os subgrupos foram identificados num primeiro momento por cores, sendo as barras azuis correspondendo às tensões mais baixas, seguidas das verdes e laranjas, chegando das vermelhas, com maiores tensões. A visualização por cores permite identificar rapidamente o subgrupo ao qual a barra pertence (Figura 3).

Para cada subgrupo foi utilizado uma secção diferente, deste modo, barras com tensões muito próximas de zero possuíam secções menores, sendo elementos mais esbeltos, aumentando de acordo com o intervalo de tensão de cada grupo. No total foram utilizadas quatro secções, buscando a melhor utilização do material.

Figura 3 - Otimização estrutural por adequação da secção

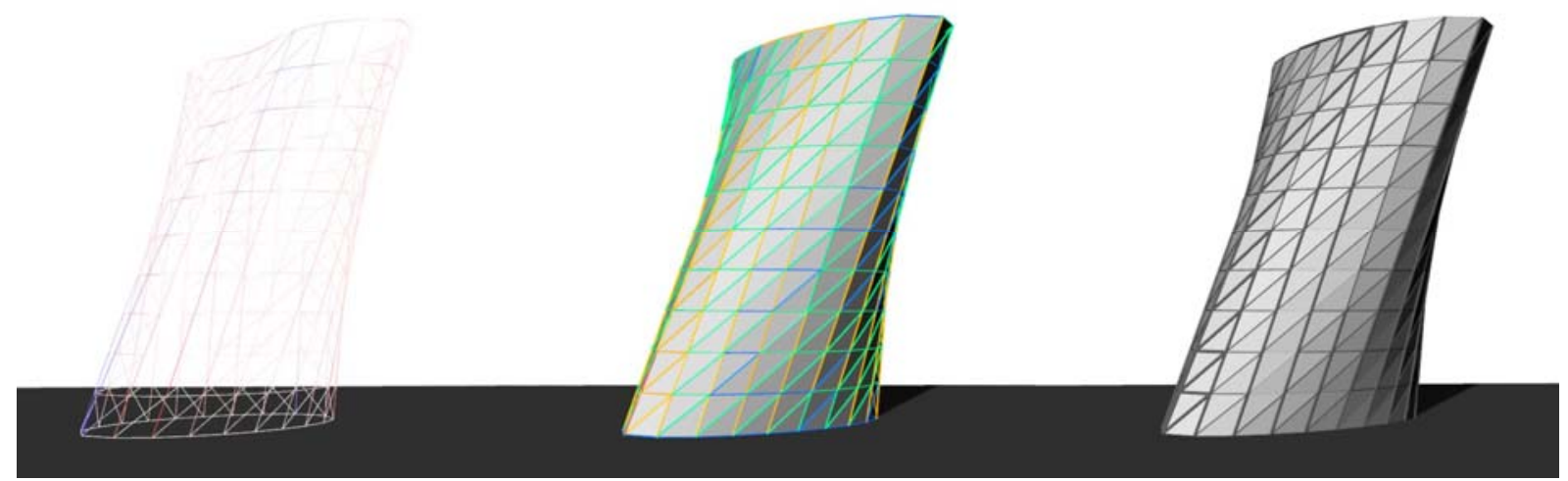

Fonte: Dos autores.

É importante ressaltar que mesmo as barras que possuiam tensão igual a zero foram mantidas, buscando garantir a estabilidade estrutural. Seria possível extrair as barras com tensões muito baixas, como já foi feito em alguns edifícios, porém estes primeiros testes buscam métodos mais simples de otimização estrutural e melhor uso dos materiais, alterando somente a secção da estrutura de acordo com o esforço de cada barra. 


\subsection{Análise de ganho térmico}

Para a análise de ganho térmico, foram utilizadas as superfícies triangulares obtidas, as quais são exportadas para o Ecotect através do plug-in Geco. Para se efetuar a exportação e, posteriormente, ler os dados corretamente, é importante ordenar as faces, acrescentar as faces de topo e base e transformá-las em mesh antes da exportação. Caso o volume seja exportado inteiro, o Geco irá transformá-lo em mesh, porém será difícil ordenar os dados fornecidos e referenciá-los às superfícies correspondentes. Caso o volume apresente aberturas, também poderão ocorrem problemas, fornecendo dados inverossímeis.

O Ecotect fornece o valor da insolação de cada superfície, sendo que, para a análise, foi utilizado o WeatherFile de São Paulo, sendo considerado como parâmetros o período do verão e horário de análise das $8 \mathrm{~h}$ às $16 \mathrm{~h}$. Ao se relacionar a insolação e área de cada superfície, obteve-se o ganho térmico desta.

É importante ressaltar que o mesmo método poderia ser utilizado em superfícies curvas, sendo que foi testada a mesma subdivisão da forma em triângulos, contudo mantendo sua forma curva. Neste teste, bem como em outros, a diferença entre os resultados do uso da superfície curva ou plana é insignificante (menor que 1\%, variando de acordo com o número de subdivisões), sendo que a análise de superfícies curvas requer um tempo maior (normalmente mais que o dobro) que das superfícies planas. Tendo estes resultados em vista, mesmo que serão utilizadas superfícies curvas, num primeiro momento, as análises e simulações podem ser efetuadas com superfícies planas, por sua rapidez e precisão.

\subsection{Aplicação de padrões}

Tendo como base os valores de ganho térmico encontrados para cada superfície, estas foram divididas em quatro grupos, identificados pelas cores verde, amarela, laranja e vermelha, de acordo com o valor crescente de seu ganho térmico. O intervalo de ganho térmico que define cada grupo foi encontrado através do uso de algoritmos genéticos, através do componente Galapagos (presente no Grasshopper), tendo o valor destes intervalos como "genoma" e o ganho térmico ideal como "objetivo".

Para cada grupo a disposição e os tamanhos das aberturas variam, apresentando uma relação fractal de quatro níveis. O primeiro grupo apresenta somente uma abertura que corresponde a $80 \%$ da área da superfície, sendo que cada superfície do segundo grupo foi subdividida em três a partir da conexão do seu centroide com os vértices da face, sendo que suas aberturas correspondem a $65 \%$ da área de cada superfície. 0 mesmo ocorre com os outros dois níveis, subdividindo a face em nove subsuperfícies com abertura de $50 \%$ e, para o quarto grupo, subdividindo em vinte e sete subsuperfícies, com abertura de $35 \%$.

Segundo a análise de gastos com condicionamento de ar realizada no Ecotect, seria necessário reduzir o ganho térmico do edifício em $70 \%$ para que os gastos de condicionamento de ar fossem próximos a zero. Para esta análise foi levado em conta o período de maior gasto de condicionamento de ar, que seria o período do verão, das $8 \mathrm{~h}$ até as $18 \mathrm{~h}$.

A distribuição das superfícies nos grupos através do Galapagos e aplicação dos padrões (Figura 4) permitiu reduzir o ganho térmico do edifício para $72 \%$. Além da redução do ganho térmico, este método de aplicação, com maior redução das aberturas nas áreas de maior ganho térmico, permite que, nas áreas de menor ganho térmico, seja possível a iluminação natural indireta dos ambientes. 
Figura 4 - Análise de ganho térmico e aplicação de padrões

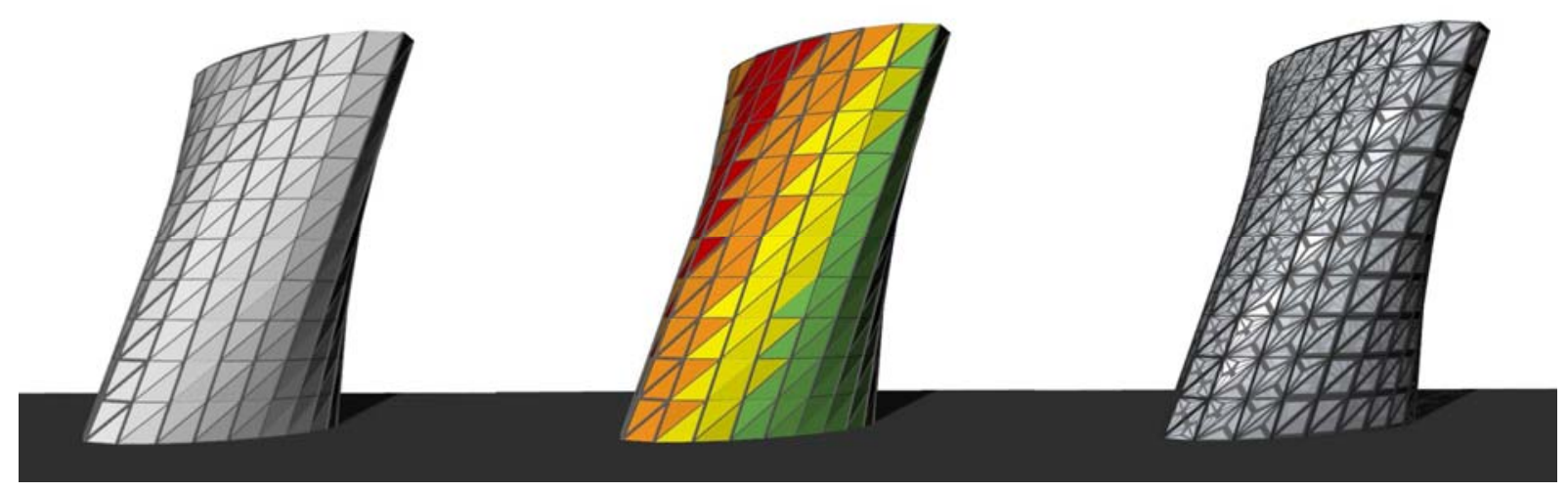

Fonte: Dos autores.

\section{RESULTADOS}

Depois de aplicado o método de otimização estrutural, a estrutura final teve seu peso reduzido em $71 \%$, se comparado com o peso da estrutura original sem otimização, que utilizava a mesma secção da barra em toda a estrutura.

Ao se utilizar a mesma secção em toda a estrutura, diversas barras ficam subutilizadas, pois as forças aplicadas a elas são significativamente menores que a tensão a qual elas resistem. Ao diminuir a secção da barra de acordo com a redução de tensão, de fato é esperada uma redução significativa na quantidade de material gasto.

No método de otimização de ganho térmico para redução de gastos com condicionamento de ar, como já citado, foi estabelecido como ganho térmico ideal o valor de $70 \%$ do ganho original, sendo que após a aplicação dos painéis perfurados, este foi reduzido em $72 \%$.

Caso fosse aplicado somente o padrão com a menor abertura (35\%), buscando reduzir ao máximo o ganho térmico do edifício, este seria reduzido para $57 \%$, um valor inferior ao ganho térmico ideal. Outro modo de se reduzir o ganho térmico para $70 \%$ seria pela aplicação de um único módulo com $62 \%$ de aberturas, contudo, estaria levando em conta o ganho térmico médio de todo o edifício, havendo áreas com ganho superior a $70 \%$ e áreas com ganho inferior, havendo necessidade de condicionamento de ar nestas áreas. Ao se utilizar diferentes padrões, pode-se controlar melhor o ganho de cada superfície, sendo que o ganho de todas aproxima-se da média (72\%).

É importante ressaltar que, em ambos os casos, a redução depende dos parâmetros utilizados. No caso da estrutura, deve-se levar em conta o material utilizado, seus valores de compressão e tração e secções comerciais. No caso do ganho térmico, deve-se levar em conta o ganho térmico ideal que está se buscando, onde a necessidade de condicionamento de ar seja nula ou próxima a zero no período das análises, sendo que não se pode reduzir o ganho térmico abaixo do nível necessário, pois seria necessário então efetuar o aquecimento do ambiente, gastando novamente com condicionamento de ar.

\section{CONCLUSÕES}

O edifício apresentado neste exercício de projeto demonstra o uso de ferramentas de análise em conjunto com métodos paramétricos que geram um edifício mais complexo, onde algumas de suas características formais provem de questões funcionais e práticas. A partir de suas fachadas, é possível compreender a distribuição das tensões estruturais a partir da diferença das secções na estrutura, bem como compreender a distribuição do ganho térmico na fachada, por meio das aberturas nos painéis (Figura 5). Deste modo, o edifício apresenta 
um caráter didático, demonstrando um modo de se tratar a solução formal e distribuição de elementos tendo como base questões funcionais e análises computacionais.

Figura 5 - Elevação frontal, direita, posterior e esqurda

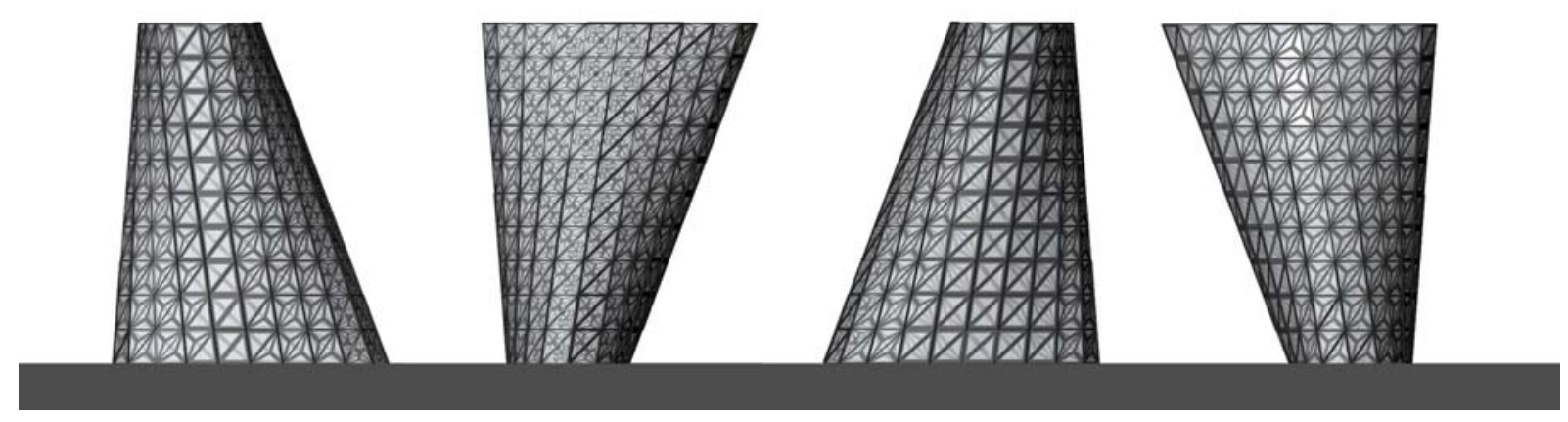

Fonte: Dos autores.

Além do edifício apresentar suas características funcionais por meio da distribuição dos elementos nas fachadas, as otimizações reduzem o material e energia gastos na construção e operação do edifício, apresentando uma solução mais ecológica e tendo como base o início do processo de projeto, não ações mitigadoras. Deve-se ressaltar que só foi levado em conta gasto energético com condicionamento de ar, demais gastos com iluminação não foram levados em conta, porém nota-se que é possível utilizar a iluminação natural indireta em certas áreas, como já foi apontado.

Como se trata de um processo baseado no método paramétrico é possível ainda modificar a geometria e parâmetros do edifício visando explorar diferentes soluções formais e funcionais. Este processo pode ser utilizado desde o início do processo de projeto, fornecendo noções do funcionamento e relações entre arquitetura, estrutura e ganho térmico solar, permitindo ao arquiteto encontrar soluções que levem em conta todos estes fatores, ponderando-os.

\section{CONSIDERAÇÕES FINAIS}

Como exercício de projeto, este exemplo conseguiu demonstrar o uso da parametrização e simulações computacionais na busca por soluções integradas e otimizadas. Demonstrou também como é possível tratar a envoltória do edifício de modo que seus elementos apresentam soluções formais e distribuição de elementos instigantes e que, ao mesmo tempo, respondam às questões funcionais do edifício.

Deve-se considerar que existem diversas formas de otimização estruturas e de envoltória, sendo que aqui foram tratadas somente duas formas que eram adequadas aos objetivos da pesquisa e à geometria na qual foi aplicada. Em outras formas, como edifício em formato de paralelepípedo, soluções como a de controle de ganho térmico podem não ser as mais eficazes ou formalmente instigantes, sendo necessário simular as possibilidades de otimização e escolher a mais adequada aos objetivos e geometria estabelecidos.

É importante também considerar que as otimizações efetuadas levaram em conta os valores de massa estrutural e ganho térmico, porém outros fatores importantes estão presentes na construção civil que devem ser levados em conta. Entre eles, podemos citar as questões econômicas, culturais, qualificação de mão-de-obra, outros fatores ambientais (como incidência de ventos) etc.

No que diz respeito à análise estrutural fornecida pelo plug-in Karamba, esta é usada somente para o pré-dimensionamento estrutural, não substituindo a análise fornecida por softwares mais avançados de simulação. Seu uso permite compreender o funcionamento 
das questões estruturais envolvidas na proposta, permitindo ao arquiteto alterá-la.

Levando em conta estas considerações e limitações, os métodos utilizados foram eficazes e podem ser utilizados em diversos casos, com os devidos ajustes. Por sua questão paramétrica, permite a rápida exploração de soluções integradas, sendo uma ferramenta importante no início do processo de projeto e seu desenvolvimento. Este processo permite também analisar com maior precisão o edifício do que só utilizando regras práticas, ao mesmo tempo em que não requerendo softwares avançados de simulação.

Como já citado, esta pesquisa ainda está em desenvolvimento, sendo que estão sendo desenvolvidos vários exercícios de projeto e estudos de caso visando compreender diversos métodos de otimização e melhor uso dos materiais. No que diz respeito à questão estrutural, além de continuar com o uso de elementos de diversas secções na estrutura, será explorada a possiblidade de redução de elementos estruturais, mantendo-se a mesma secção. Outra possibilidade que está sendo explorada na pesquisa é o uso da estrutura como elemento sombreador, utilizando-se como brise.

No que diz respeito aos softwares utilizados, é importante ressaltar que o programa Ecotect apresenta-se desatualizado, sendo que já está sendo substituído na pesquisa pelo programa EnergyPlus, utilizando o plug-in Honeybee, para Grasshopper. O Ecotect foi utilizado no início desta pesquisa por ter sido utilizado anteriormente em pesquisa desenvolvida pelos autores e por sua facilidade no uso e comunicação com o Grasshopper.

\section{AGRADECIMENTOS}

À FAPESP, pela bolsa concedida, e ao LAPAC e UNICAMP, pelo apoio e infraestrutura concedida.

\section{REFERÊNCIAS}

ANDRADE, M. Projeto performativo na prática arquitetônica recente: estrutura conceitual. UNICAMP, 2012.

BURRY, J.; BURRY, M. The New Mathematics of Architecture. Londres, Ed. Thames \& Hudson, 2010.

CAMPOS, F.; CELANI, G. Estudo de otimização de coberturas responsivas à insolação através da parametrização. In XV ENTAC, 2014, Maceio, Anais... Maceio, 2014.

DIMCIC, M. What is your profession? Programming Architecture, 2013. Disponível em <http://www.youtube.com/watch?v=jwRPQrxxNDA> Acesso em: 26 abril 2014.

KOLAREVIC, B.; MALKAWI, A. Performative architecture: beyond instrumentality. Nova York, Spon Press, 2005.

OXMAN, R.; OXMAN, R. The new structuralism: Design, engineering and architectural Technologies. In: Architecture Design. Wiley, Londres, 2010.

SEDREZ, M.; CELANI, G. Ensino de projeto arquitetônico com a inclusão de novas tecnologias: uma abordagem pedagógica contemporânea. Pós V. 21 N. 35, São Paulo. Junho 2014. 